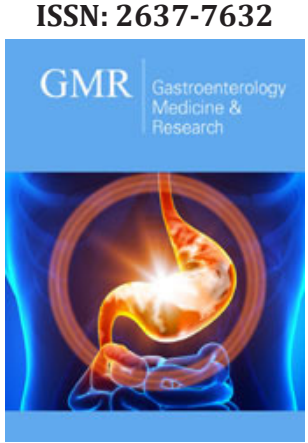

*Corresponding author: Arcelia Guerson Gil, MD, Internal Medicine, Jacobi Medical Center, USA

Submission: 非 February 14, 2020

Published: 帮February 24, 2020

Volume 4 - Issue 3

How to cite this article: Arcelia Guerson Gil, Pawan Rastogi, Saeed Asiry, Sammy Ho. Not So Smooth Swallowing-Posterior Mediastinal Smooth Muscle Tumor Presenting as Dysphagia.Gastro Med Res. 4(3). GMR.000588. 2020.

DOI: 10.31031/GMR.2020.04.000588

Copyright@ Arcelia Guerson Gil, This article is distributed under the terms of the Creative Commons Attribution 4.0 International License, which permits unrestricted use and redistribution provided that the original author and source are credited.

\section{Not So Smooth Swallowing-Posterior Mediastinal Smooth Muscle Tumor Presenting as Dysphagia}

\author{
Arcelia Guerson Gil ${ }^{1 *}$, Pawan Rastogi ${ }^{2}$, Saeed Asiry ${ }^{3}$ and Sammy Ho \\ ${ }^{1}$ Internal Medicine, Jacobi Medical Center, USA \\ ${ }^{2}$ Gastroenterology, Montefiore Medical Center, USA \\ ${ }^{3}$ Pathology, Montefiore Medical Center, USA \\ ${ }^{4}$ Gastroenterology, Montefiore Medical Center, USA
}

\section{Abstract}

Among etiologies for posterior mediastinal masses, esophageal smooth muscle tumors are uncommon; especially in the upper third of the esophagus as highlighted by our patient's case. Endoscopic ultrasonography (EUS) has become an effective mode of evaluation for mediastinal masses. Allowing for a minimally invasive approach to achieving tissue diagnosis.

Keywords: Dysphagia; EUS-FNA; Leiomyoma; Mediastinum; Endoscopic ultrasonography; Fine needle aspiration

\section{Introduction}

The presence of a smooth muscle tumor within the posterior mediastinum is a rare condition with an incidence rate of $\sim 8 / 10,000$. While smooth muscle tumors usually arise from the middle and lower thirds of the esophagus, our patient presented with a posterior mediastinal lesion compressing on the upper third with symptoms of progressive solid food dysphagia. This case of a smooth muscle tumor compressing on the upper third of the esophagus merits attention due to its rarity.

\section{Case Presentation}

A 44-year-old male with a history of HTN presented with progressive dysphagia to solid food over the last 6 months. Physical examination, vital signs and initial basic laboratory work up were largely unremarkable. CT scan of the chest with contrast revealed a $4 \mathrm{~cm} \mathrm{x} 4 \mathrm{~cm}$ posterior mediastinal mass at $\mathrm{C} 2-\mathrm{C} 4$ levels behind the trachea, with resultant distortion of the esophagus (Figure 1). Endoscopic ultrasonography (EUS) revealed extrinsic compression in the upper third of the esophagus by a large hypoechoic lesion (Figure 2). Fine needle aspiration (FNA) was performed with cytology revealing smooth muscle tumor with nuclear atypia raising concern for leiomyoma (Figure 3). As a result, patient was referred to our Cardiothoracic Surgery Team for surgical excision (Figure 4).

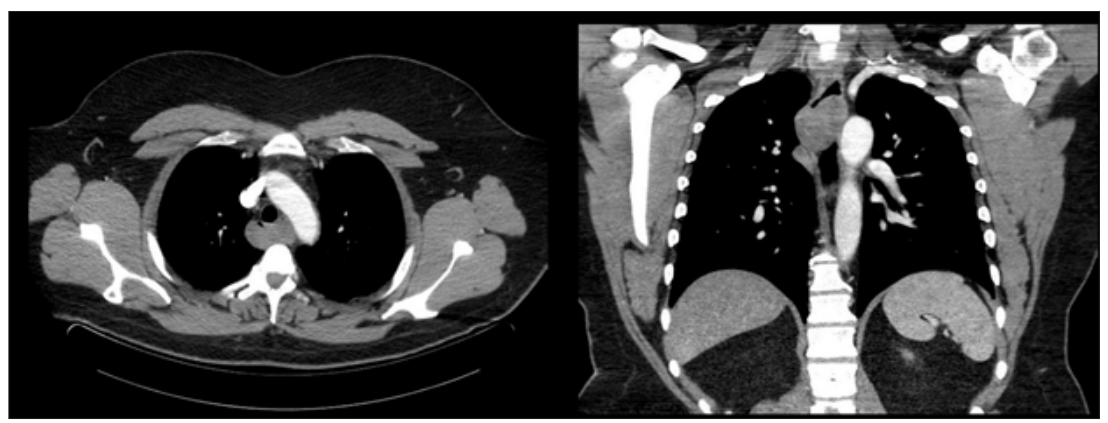

Figure 1: Contrast-enhanced computed tomography (CT) revealed a $4 \mathrm{~cm}$ $\mathrm{x} 4 \mathrm{~cm}$ posterior mediastinal mass at C2-C4 levels behind the trachea. 


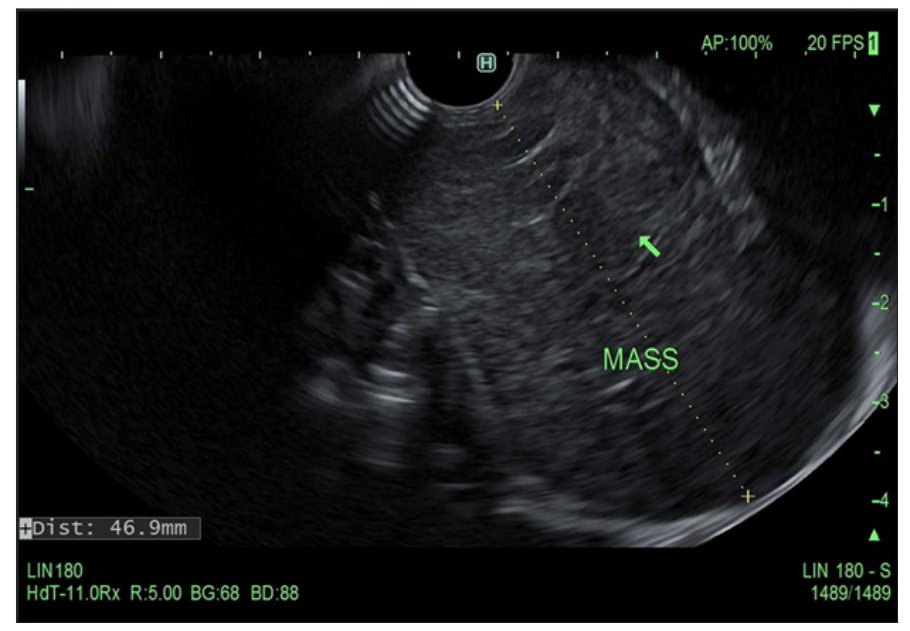

Figure 2: A round intramural (subepithelial) lesion was found in the upper third of the esophagus. The lesion was hypoechoic and heterogenous. The endosonographic borders were well-defined.

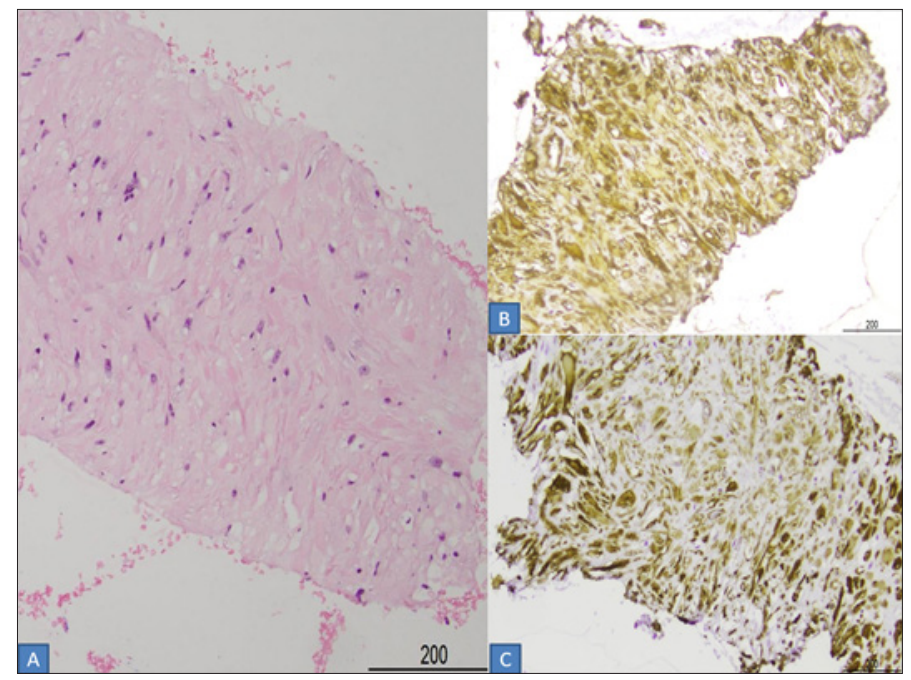

\section{Figure 3:}

A: Smooth muscle tumor with cytologic atypia (H\&E 200x). The tumor cells are positive for immunohistochemical stains SMA (smooth muscle actin;

B: and desmin (C)) (200x).

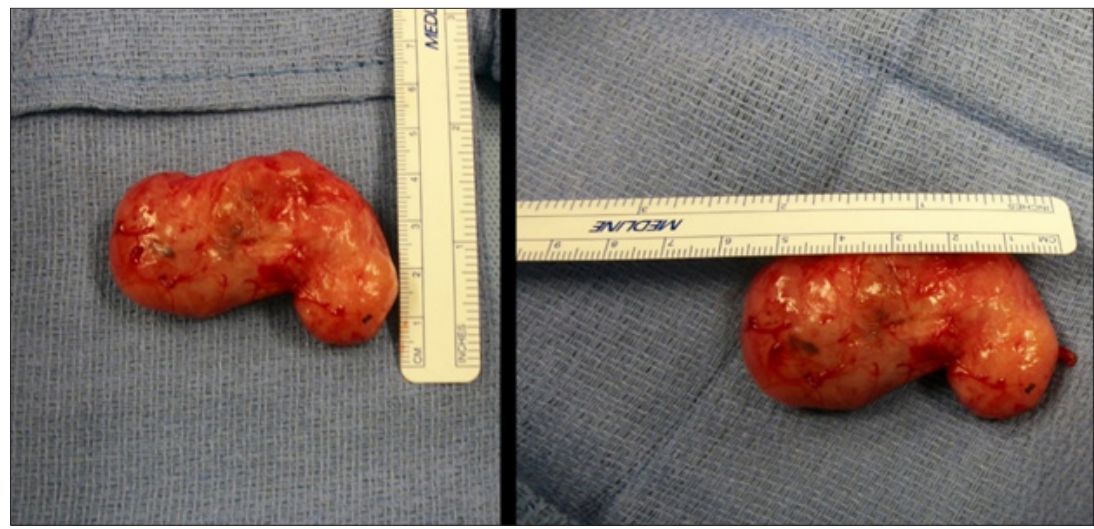

Figure 4: Macroscopic appearance of the adrenal mass, measuring $4.5 \mathrm{~cm} \times 5.5 \mathrm{~cm}$ in diameter. 


\section{Discussion}

The mediastinum is limited by the pleural cavities laterally, the thoracic inlet superiorly, and the diaphragm inferiorly. Furthermore, the mediastinum is divided into anterior, middle and posterior compartments. The anterior mediastinum is comprised of the thymus, fat, and lymph nodes. The middle mediastinum is made of the heart, pericardium, ascending and transverse aorta, trachea, bronchi and lymph nodes, lastly the posterior mediastinum contains the descending thoracic aorta, esophagus, azygous vein, autonomic ganglia and nerves, thoracic lymph nodes, and fat. Throughout medical education the differential diagnosis of a mediastinal mass is dictated by anatomic location as follows: Anterior-Thymoma, Teratoma, Thyroid disease and Lymphoma; Middle-Pericardial cyst, \& Bronchogenic cyst; Posterior - Neurogenic tumor, Bronchogenic cyst, \& Enteric cyst [1]. Among the etiologies for posterior mediastinal masses, esophageal smooth muscle tumor is an uncommon finding, especially in the upper third of the esophagus, as highlighted by our patient's case. EUS has become an effective modality for the evaluation of mediastinal masses, providing a minimally invasive approach to achieving tissue diagnosis [2]. This case demonstrates the importance of breaking the traditional thought process and maintaining a broad differential diagnosis while working up a posterior mediastinal mass.

\section{References}

1. Duwe BV, Sterman DH, Musani AI (2005) Tumors of the Mediastinum. Chest 128(4): 2893-2909.

2. George M, Carter YM (2020) Esophageal Leiomyoma. StatPearls Publishing, Treasure Island, Florida, USA.

For possible submissions Click below: 